Religare, ISSN: 19826605, v.16, n.1, agosto de 2019, p.370-401.

\title{
Separação Estado-religiões e diferenciação das esferas sociais como secularização? Correlacionando os indices de diferenciação funcional e religiosidade na Europa
}

\author{
State-religions separation and differentiation of social spheres \\ as secularization? Correlating the indexes of functional \\ differentiation and religiosity in Europe
}

Jorge Botelho Moniz ${ }^{1}$

\section{Resumo}

Muitas críticas às teorias típicas da secularização têm surgido nas décadas recentes. Uma miríade de alternativas conceptuais e teóricas surgiu; porém, os cientistas sociais continuam sentindo dificuldades em responder, de forma sustentada, a uma questão fundamental do debate da secularização: quais os processos da modernidade (se é que há algum) que conseguem melhor descrever as mutações ou deslocações atuais do religioso nas sociedades hodiernas? Com este trabalho pretendemos então dar resposta a dois argumentos fundamentais: a ideia de que foi atingido um impasse no debate acerca da secularização e de que são necessárias novas metodologias e estratégias teóricas e empíricas para se entenderem os efeitos da modernização na religião. Deste modo, inspirando-nos nas asserções de uma das teorias mais relevantes e sistemáticas da secularização - a diferenciação funcional -, sugerimos a formação de um índice de diferenciação funcional que seja correlacionável com uma medida de religiosidade individual. Utilizaremos uma metodologia qualitativa, analisando as proposições teóricas da diferenciação funcional e suas dimensões internas, e quantitativa, mensurando, através de fontes como o Eurostat, a OCDE e o ARDARAS, suas dimensões e construindo uma medida de diferenciação funcional. Conclui-se que, para o grupo de países europeus selecionado e para o período temporal estudado (1999-2015), a teoria da secularização, que afirma que as sociedades mais diferenciadas funcionalmente são menos religiosas, não tem validade empírica.

Palavras-chave: Secularização; Diferenciação funcional; Índice; Religião.

\begin{abstract}
Classical secularization theories had suffered strong criticism throughout recent decades. A myriad of conceptual and theoretical alternatives emerged, but social

\footnotetext{
${ }^{1}$ Doutor em Ciência Política, especialidade de Teoria e Análise Política, pela Universidade Nova
} de Lisboa (Portugal).
\end{abstract}


Religare, ISSN: 19826605, v.16, n.1, agosto de 2019, p.370-401.

scientists still have difficulty answering a fundamental question in the secularization debate: which process of modernity (if any) better describes the current mutations or displacements of religion in today's societies? This research seeks to answer two fundamental arguments: the idea that we have reached a deadlock in the secularization debate, and that we need new theoretical and empirical approaches to understand the effects of modernity's processes on religion. In order to do this and inspired by the assumptions of one of the most prominent and systematized theories of secularization - functional differentiation - we propose the creation of an index of functional differentiation that correlates with a measure of individual religiosity. On the one hand, we will use qualitative research, examining the theoretical propositions of functional differentiation and its internal dimensions; on the other hand, we will resort to quantitative research, computing, through some sources such as the Eurostat, the OECD, and the ARDA-RAS, its dimensions and creating a model of functional differentiation. We conclude that, for the set of selected European countries and for the time period considered (1999-2015), the secularization theory, which asserts that more functionally differentiated societies are less religious, has no empirical validity.

Keywords: Secularization; Functional differentiation; Index; Religion.

\section{Introdução}

Os debates sobre religião têm sido marcados, nas últimas décadas, por um embate teórico entre duas narrativas sobrepostas, embora aparentemente antitéticas. De um lado, a ideia de uma perda de relevância social da religião, preconizada pelos defensores das teorias da secularização (NORRIS \& INGLEHART, 2004; PICKEL, 2017). De outro lado, a concepção do regresso (do significado social) das religiões (BERGER, 1999; FOX, 2008).

Contudo, para Casanova (2007, p. 3), chegou-se a um "ponto morto neste debate", pois a teoria tradicional da secularização adequa-se, relativamente bem, à realidade europeia, mas não à norte-americana, enquanto a narrativa da vitalidade dos mercados religiosos (desregulados) é relativamente eficaz para explicar a realidade dos Estados Unidos da América, mas não a da Europa. Os teóricos afirmam ser necessária uma mudança de rumo das pesquisas sobre esse fenômeno (HALIKIOPOULOU, 2011), porque, chegados a este "beco sem saída para o estudo sociocientífico da religião" (WOHLRAB-SAHR \& BURCHARDT, 
Religare, ISSN: 19826605, v.16, n.1, agosto de 2019, p.370-401.

2017, p. 144), o debate sobre a secularização tem-se tornado "infrutuoso" (CASANOVA, 2007, p. 1, 3).

Tendemos a concordar com essas proposições. Todavia, relembramos que, com a integração, aplicação e desenvolvimento da ideia das múltiplas modernidades de Eisenstadt (2000) no debate sobre a secularização surgiram uma série de inovações conceptuais e epistemológicas sobre o lugar do religioso no mundo, nomeadamente o ocidental ${ }^{2}$. Em particular, as ideias de dessecularização (BERGER, 1999), pós-secularização (Habermas, 2008), múltiplas secularizações (NORRIS \& INGLEHART, 2004; MARTIN, 2005; DEMERATH, 2007; CASANOVA, 2011) ou secularidades (WOHLRAB-SAHR \& BURCHARDT, 2012) e secularização contextual (CASANOVA, 2007; PICKEL, 2011; BENPORAT \& FENIGER, 2013; MONIZ, 2017a). O problema desta miríade de inovações ou renovações teóricas e conceptuais é que, segundo Pickel (2017), mantêm em suspenso uma questão que ainda não foi decidida definitivamente. Ou seja, que processo da modernidade, se é que há algum, consegue descrever as mutações ou deslocações do religioso nas sociedades contemporâneas? Efetivamente, a maioria dessas conceptualizações mais recentes é sustentada cientificamente pela análise de fatores históricos, pelas reflexões de cariz sociológico e/ou filosófico ou pela descrição de fenômenos sociopolíticos. Raros têm sido os estudos que associam a dimensão teórica a uma dimensão mais empírica - estatística - que analise com rigor os desenvolvimentos (positivos ou negativos) dos fenômenos religiosos. Mesmo nos casos em que isso sucedeu (NORRIS \& INGLEHART, 2004; PICKEL, 2017) os estudos foram baseados, não raras vezes, em variáveis uni ou bidimensionais, negligenciando a sistematização das várias teorias da secularização e das suas alternativas teóricas para compreender e interpretar os fenômenos de deslocação, revitalização ou declínio do religioso nas sociedades contemporâneas.

\footnotetext{
${ }^{2}$ Os termos ocidental ou ocidente e seus derivados devem ser compreendidos à luz da ideia de mundo multicivilizacional descrito na obra Choque de civilizações de Samuel P. Huntington (1996).
} 
Religare, ISSN: 19826605, v.16, n.1, agosto de 2019, p.370-401.

Essa análise avulsa, ainda que longitudinal, de inquéritos de bancos de dados internacionais - por exemplo, a crença em Deus ou a frequência a serviços religiosos - não só não capta as dimensões da religiosidade (individual e difusa) contemporânea, como não examina a fundo os argumentos dos teóricos da secularização. Por conta dessa incúria, desconhecemos a existência de algum estudo que tenha procurado e que tenha logrado (como nós tentaremos) condensar esses argumentos teóricos em variáveis empíricas mensuráveis e que, além disso, as tenha contraposto a níveis multidimensionais e abrangentes de religiosidade. Consideramos que só através de uma tal metodologia poderemos responder à supracitada interrogação de Pickel (2017) e, assim, compreender se as teorias da secularização ou as suas alternativas teóricas são válidas para justificar as mutações do religioso, sobretudo, ao nível micro (individual).

O nosso artigo se foca na teoria da diferenciação funcional, não só porque a consideramos uma das teorias nucleares da secularização (MONIZ, 2017b) concomitantemente com as suas sub-teorias clássicas da racionalização e societalização e com a sua versão mais moderna da segurança existencial ${ }^{3}$-, mas também porque é apontada como um dos fatores-chave mais consensuais da modernização que explica a diminuição do significado microssocial da religião.

\section{Sobre a teoria da diferenciação funcional}

O núcleo central desta camada é representado por uma teoria de diferenciação funcional de inspiração durkheimiana. Ela diz respeito ao processo pelo qual o Estado e a política reduzem os sistemas religiosos tradicionais a um subsistema social, entre outros, fazendo-os perder a sua proeminência e relevância em sociedades modernas funcionalmente diferenciadas (DURKHEIM, 1984 [1893]). Isto é, com o crescimento da autonomia, especialização, competição e tensão entre as diferentes forças sociais, as autoridades religiosas

\footnotetext{
${ }^{3}$ Para mais desenvolvimentos sobre o que designamos de teorias nucleares ou camadas internas da secularização, cf. Moniz (2017b).
} 
Religare, ISSN: 19826605, v.16, n.1, agosto de 2019, p.370-401.

institucionalizadas perdem o controlo sobre determinadas funções sociais, tais como: a política, economia, educação, família, saúde ou assistência social.

Na literatura, o fenômeno da diferenciação per se não é discutível (HELLEMANS, 1998, p. 75). A questão principal não é tanto o acontecimento dos seus processos, mas as consequências que têm para a religião. Segundo Gorski (2000, p. 139-142), a partir dos anos 1960 conseguem-se detetar três proposições básicas, mas não estanques: declínio, privatização e transformação.

A tese do declínio é uma das mais visíveis. Para Wilson (1969 [1966], p. xiv), por meio deste processo de diferenciação ou autonomização, a sociedade deixa de necessitar das funções latentes da religião e, consequentemente, as instituições e as ações religiosas perdem sua relevância social. Assim, o fenômeno religioso em geral e as autoridades e organizações religiosas em particular vêem o seu significado social ser circunscrito, diminuído ou até desintegrado (MARTIN, 1978, p. 3; LUHMANN, 1995, p. 191).

A proposição da privatização é, sobretudo, avançada por Luckmann (1967). Para o autor, a diferenciação funcional deriva de uma ação política deliberada de desenvolvimento de esferas institucionais especializadas (LUCKMANN, 1967, p. 39-40, 101). A redução do espaço de ação e influência das instituições religiosas transforma a religião em uma realidade crescentemente subjetiva e privada (LUCKMANN, 1967, p. 85-86). Também em Berger (1990 [1967], p. 107) o fenômeno da diferenciação não provoca apenas mudanças sócioestruturais na religião; antes, passa a manifestar-se mais fortemente como retórica pública e virtude privada (BERGER, 1990 [1967], p. 134). Na mesma linha, Luhmann (1995, p. 218-221) considera que a criação e especialização de subsistemas sociais seculares podem estimular a individualização das escolhas dos indivíduos.

Por fim, analisamos a ideia da transformação. Parsons (1960) foi um dos primeiros a escrever sobre o processo de diferenciação e sobre suas consequências para a religião. Tal como Luckmann, Parsons acredita que, à 
Religare, ISSN: 19826605, v.16, n.1, agosto de 2019, p.370-401.

medida que as sociedades se complexificam e diferenciam funcionalmente, a influência institucional das igrejas ocidentais vai-se confinando à esfera privada. Contudo, por oposição a Luckmann, ele acredita que a manutenção dos valores cristãos se mantém sadia nessas sociedades. Com efeito, Parsons (1977) afirma que esses valores haviam passado por um processo de generalização, formando o núcleo sagrado do sistema social e das suas partes constituintes. Assim, enquanto o sagrado havia ficado mais fragmentado, não tinha, porém, ficado menos público. Tal como Parsons, Berger (1990 [1967], p. 133) acredita que a religião tradicional continua tendo impacto público, porquanto, em condições de diferenciação estrutural, a religião passa a poder se especializar exclusivamente em suas próprias funções religiosas, logrando trabalhar em novos modelos de relação com os indivíduos e os Estados modernos. Por exemplo, através do desenvolvimento de uma religião civil (BELLAH, 1975).

Tendo em conta essas três asserções fundamentais (declínio, privatização e transformação), relativamente aos efeitos da diferenciação funcional na religiosidade, prosseguimos para a próxima seção deste artigo onde consideramos a sua multidimensionalidade. Isso nos permite não só operacionalizar este conceito, tornando-o mensurável, mas também, correlacioná-lo, ulteriormente, com uma medida de religiosidade que coloque à prova suas três proposições básicas.

\section{Diferenciação funcional como conceito multidimensional}

As três proposições da diferenciação funcional têm perspectivas diferentes sobre os seus efeitos na religiosidade. Todavia, no geral, esta teoria descreve, a partir de uma ideia evolutiva (a passagem de sistemas socias estratificados para sistemas funcionalmente diferenciados), o modo como um determinado sistema social (político, religioso, econômico, educacional, entre outros) se diferencia dos outros pela função (autônoma, especializada e competitiva) que desempenhada no sistema geral. Ou seja, com a hipercomplexidade dos fenômenos da 
Religare, ISSN: 19826605, v.16, n.1, agosto de 2019, p.370-401.

modernidade - sobretudo, ao nível estatal, com o conceito de separação de poderes -, os diferentes sistemas sociais tendem a aumentar sua complexidade interna, impedindo que qualquer outro o possa controlar, dominar ou substituir. No decorrer dessa crescente autonomização, especialização e competição entre diferentes esferas sociais, os sistemas religiosos tradicionais (que, no passado, teriam operado dentro de uma lógica primária hierárquica e mono-estrutural) tornam-se subsistemas sociais, como os outros, perdendo proeminência no desempenho de determinadas funções sociais pelas quais haviam sido, anterior e quase exclusivamente, responsáveis. Por exemplo: assistência social, integração ou educação.

São dois os argumentos mais sistematicamente referidos pelos teóricos da diferenciação funcional: em primeiro lugar, e mais destacadamente, a separação entre política e religião, representativa do núcleo desta teoria. De acordo com Rueschemeyer (1977, p. 16), a separação de poderes é "talvez o caso mais dramático de diferenciação", porque é através desta ação política deliberada (LUCKMANN, 1967, p. 39-40, 101) que o processo de diferenciação funcional se inicia e que a esfera religiosa é obrigada a competir pelo seu papel (espiritual, assistencial ou educacional) com uma pluralidade de sistemas funcionais modernos, complexos, não redundantes e não hierárquicos ${ }^{4}$. A partir daí, segundo Wilson (2016, p. 62), não só as novas esferas sociais (seculares) substituem o papel das instituições religiosas, como ainda, o papel da religião "perde rapidamente sua preeminência e se torna praticamente residual". Esta gradual perda de influência das esferas religiosas sobre várias atividades humanas é estimulada pelo segundo fator, ou melhor, conjunto de fatores,

\footnotetext{
${ }^{4} \mathrm{O}$ processo de emergência duma razão estatal e de desmonopolização do religioso de diferentes esferas sociais dá-se, no ocidente, com a Paz de Vestefália de 1648 e aprofunda-se com as revoluções liberais americana e francesa do século XVIII e com o Kulturkampf e o positivismo do século XIX. Estes desenvolvimentos conduziram os primeiros cientistas sociais, nomeadamente Max Weber nos seus estudos sobre a ética protestante e a sociologia do direito, a associar os processos da modernidade à secularização/racionalização nos campos jurídico e político. Esta modernização político-jurídica obrigou, segundo o argumento, a religião a atuar num terreno onde competem vários intervenientes.
} 
Religare, ISSN: 19826605, v.16, n.1, agosto de 2019, p.370-401.

citados pelos teóricos e que derivam da diferenciação funcional: a autonomização, especialização e competição entre as esferas sociais. À medida que se vão autonomizando, aumenta a "pressão da competição" (WILSON, 2016, p. 115) entre elas. Para sobreviverem nessas condições as esferas sociais passam por um processo de "especialização funcional" (LUCKMANN, 1967, p. 95) marca a rutura entre a sociedade tradicional e a sociedade industrial moderna que é uma marca distintiva deste processo geral de diferenciação (PARSONS, 1960, p. 207).

Em conclusão, podemos dizer que a teoria da diferenciação funcional tem duas dimensões internas fundamentais: a separação Estado-religiões e a autonomização, especialização e competição.

Estabelecidas as dimensões internas da diferenciação, pudemos proceder à recolha de dados (itens/indicadores) que integrassem e dessem corpo a cada uma dessas duas dimensões. Recorremos, essencialmente, a dados de três fontes: do Eurostat, da OCDE - Organização para a Cooperação e Desenvolvimento Econômico e do ARDA - Association of Religion and Data Archives. O Eurostat, fundado em 1953, é a divisão estatística da UE - União Europeia. O seu estudo longitudinal existe desde meados do século XX, mas tem-se solidificado e sistematizado desde o final dessa mesma centúria, focando-se, entre outros, em estatísticas sobre economia e finanças, população e condições sociais, indústria, comércio e serviços e ciência e tecnologia, essencialmente, na UE dos 28. A OCDE (iniciada em 1948, mas oficialmente fundada em 1961) recolhe e trata, longitudinalmente (desde a década de 1950), os dados de mais de 30 países espalhados pelo mundo. Os dados estatísticos aí recolhidos cobrem diversas áreas, nomeadamente o desenvolvimento, a educação e formação, a ciência e tecnologia, as finanças ou a produtividade. Esses bancos de dados são fundamentais para construir a segunda dimensão da diferenciação. Neste contexto importa salientar que, pela dificuldade enfrentada na composição dessa dimensão autonomização, especialização e competição, tivemos de recorrer a 
Religare, ISSN: 19826605, v.16, n.1, agosto de 2019, p.370-401.

alguns itens cuja cronologia dos valores agregados se afasta um ano para baixo (1998) do nosso período de análise. Isso é mais evidente nos itens sobre regulação, entendidos aqui enquanto antônimos de autonomização e competição.

No que concerne à primeira dimensão, pela sua especificidade, tivemos de recorrer a uma das bases de dados públicas mais recentes, completas e úteis ao nível comparativo sobre o nível de separação política e religião, o ARDA Association of Religion and Data Archives. Esta associação, coordenada por Jonathan Fox e composta por uma equipa de investigadores reconhecidos na área, como Roger Finke, elaborou duas rondas de estudo abrangentes às quais deu o nome de projeto RAS - Religion and State (ronda 1: 1990-2002; ronda 2: 20032008), sediado na Universidade Bar-Ilan (Israel). Por conta do período de análise do nosso estudo, recolhemos apenas dados da segunda ronda do RAS que é composto por 147 indicadores e que, entre outras coisas, ajudam a medir os índices de regulação e favoritismo estatal face à religião ou de regulação social e de restrições à ação religiosa, num conjunto de mais de 170 países. Por sua pertinência e complementaridade (temática e cronológica) aos dados do RAS, ainda acrescentámos nesta dimensão, sobre o grau de separação, um item cuja fonte é um trabalho de Pollack e Pickel (2009, p. 149-152) sobre o nível de separação legal entre religião e Estado.

Pela sua experiência, qualidade e rigor e pelo extenso número de investigações científicas (mas também de decisões governamentais) que baseiam seus trabalhos nesses bancos de dados, consideramos que estas fontes são fidedignas e úteis para a criação de um índice de diferenciação funcional que, posteriormente, venha a ser contraposto a um de religiosidade.

Considerando as fontes supramencionadas, nosso período de análise é 1999-201555. A escolha dessas datas não é casual. Com efeito, sua escolha deve-se

\footnotetext{
${ }^{5}$ Esse período temporal corresponde, como veremos adiante, à primeira (1999) e à última datas (2015) em que, no momento de realização deste artigo, se conseguiu reunir dados para o conjunto dos países selecionados. Nem sempre conseguimos analisar os nossos indicadores, quer sejam os de religiosidade quer sejam os de diferenciação, tão longitudinalmente quanto desejado, por conta da indisponibilidade de dados para a totalidade do nosso período temporal de análise.
} 
Religare, ISSN: 19826605, v.16, n.1, agosto de 2019, p.370-401.

ao fato de as formas mais modernas (individualizadas e indeterminadas) de religião e a diversidade das suas expressões só terem sido estudadas, pelas ciências sociais de forma mais sistemática, nas últimas décadas do século XX. Ou seja, se só a partir desse período os investigadores mostraram maior sensibilidade para a difusão e diversidade das expressões religiosas modernas, isso significa que, até então, os dados estatísticos disponíveis dificilmente contemplariam dimensões da religiosidade individual que se pudessem contrapor a variáveis independentes como a diferenciação funcional.

Assim sendo, explicadas as questões teóricas, fontais e temporais e adaptando-as às fontes disponíveis nos bancos de dados, ponderámos os seguintes indicadores para medir cada uma das dimensões teóricas da diferenciação funcional:

1. Separação Estado-religiões:

a. Regulação governamental da religião (fonte: ARDA-RAS6).

b. Favoritismo governamental à religião (fonte: ARDA-RAS).

c. Regulação social da religião (fonte: ARDA-RAS).

d. Perseguição religiosa (fonte: ARDA-RAS).

e. Pontuação Estado e Religião (fonte: ARDA-RAS).

f. Medida composta de regulação e restrições na maioria ou em todas as religiões (fonte: ARDA-RAS).

g. Medida composta de discriminação religiosa contra as minorias religiosas (fonte: ARDA-RAS).

h. Medida composta de legislação religiosa (fonte: ARDA-RAS).

i. Grau de separação legal entre igreja e Estado (fonte: Pollack \& Pickel, 2009).

\footnotetext{
${ }^{6}$ Visto que os próprios dados do ARDA aqui mencionados são medidas compostas (índices), sendo construídas através duma miríade de itens, para se entender o que cada uma significa exatamente e, por consequência, quais os itens que as compõem, aconselhamos a consulta da plataforma do RAS, citada nas referências. Em particular, seu "Religion and State Codebook: Round 2 (version 5)", 2012.
} 
Religare, ISSN: 19826605, v.16, n.1, agosto de 2019, p.370-401.

2. Autonomização, especialização e competição:

a. Empresas em setores de alta-tecnologia (fonte: Eurostat).

b. Recursos humanos em ciência e tecnologia (fonte: Eurostat).

c. Especialistas de tecnologias de informação e comunicação (fonte: Eurostat).

d. Total dos recursos humanos escolares (fonte: OCDE).

e. Total do emprego nas áreas social e da saúde (fonte: OCDE).

f. Despesa pública com a família, os idosos, os sobreviventes, os incapacitados e os doentes (fonte: OCDE).

g. Cobertura dos cuidados de saúde (fonte: OCDE).

h. Regulação do mercado de produtos (fonte: OCDE).

i. Regulação na energia, transporte e comunicações (fonte: OCDE).

j. Regulação no comércio de retalho (fonte: OCDE).

k. Barreiras à concorrência - restrições ao comércio de serviços (fonte: OCDE).

1. Indicador de competitividade: custos unitários de trabalho e preços no consumidor (fonte: OCDE).

m. Restrição regulatória no investimento estrangeiro direto (fonte: OCDE).

O índice de diferenciação funcional é composto por 22 itens $^{7}{ }^{8}$. A sua construção foi muito desafiante, por causa da dificuldade em encontrar

\footnotetext{
7 Este índice é construído a partir de diferentes bases de dados que, naturalmente, usam diferentes metodologias para medir dimensões de análise distintas. A utilização de diferentes bases de dados para compor índices é uma prática habitual, por exemplo: o Better Life Index da OCDE, o Human Development Index da UNDP - United Nations Development Programme, o Religious Diversity Index do Pew Research Center ou os índices de regulação governamental ou social, favoritismo ou perseguição religiosa do ARDA. A seleção de indicadores diferentes de bases de dados distintas para compor os índices é, portanto, uma prática comum e necessária. É feita em uma lógica de complementaridade (dada a habitual escassez de dados de determinadas bases de dados para compor, por inteiro, um índice) e não de preterimento de determinados indicadores face a outros.

${ }^{8}$ Não precisamos de calcular o alfa de Cronbach para medir a consistência interna do nosso índice, porque as dimensões e os indicadores escolhidos são baseados nos pressupostos previamente definidos pelo estado da arte e não em dimensões e indicadores idealizados por nós. Todavia, consideramos que o seu cálculo é relevante, porquanto reforça a ideia de que esse
} 
Religare, ISSN: 19826605, v.16, n.1, agosto de 2019, p.370-401.

indicadores que dessem corpo aos argumentos dos teóricos da diferenciação funcional. Na dimensão separação Estado-religiões, esta tarefa foi um pouco mais fácil, por causa dos subíndices citados em rodapé nesta seção. Consideramos que o recurso a este tipo de indicadores e o seu emparelhamento conseguem captar melhor a real dimensão da diferenciação funcional. Fazem-no melhor, no nosso entender, do que as tentativas de criação de uma variável diferenciação baseada em escalas microssociais e uni ou bidimensionais (PICKEL, 2017), do que as que se baseiam no mero estabelecimento de critérios legais de separação (POLLACK \& PICKEL, 2009) ou do que as que se sustentam na percepção que os indivíduos têm das funções das autoridades religiosas (NORRIS \& INGLEHART, 2004), porque engloba a totalidade da dimensão política, legal ou social do fenômeno de diferenciação. Outra questão a sublinhar, relativamente à dimensão separação, é o fato de integrarmos itens não considerados habitualmente na análise da diferenciação funcional, por exemplo o favoritismo ou a discriminação religiosa. Primeiro importa explicitar que ambas são analisadas a um nível macro, pois estão ligadas ao modo como os Estados favorecem ou discriminam uma ou várias religiões. Depois, elas são consideradas na construção do nosso índice, porque, se forem entendidas dentro da lógica da diferenciação (menos interferência do Estado - i.e., maior autonomia das esferas religiosas - é igual a mais diferenciação), podemos compreender que menos favoritismo ou discriminação estatal face às religiões possa ser sinônimo de maior diferenciação funcional.

No que diz respeito à sua segunda dimensão - autonomização, especialização e competição - as dificuldades em encontrar itens que pudessem medir a diferenciação funcional foram ainda maiores. Isso se deve, em parte, ao fato de, contrariamente à sua primeira dimensão, não haver trabalho empírico aí desenvolvido, pelo que tivemos de investigar e criar de raiz o nosso conjunto de

conjunto de indicadores é internamente consistente. Seguindo os níveis de fiabilidade aceites pela academia (MARÔCO \& GARCIA-MARQUES, 2006; BRITES, 2015), nomeadamente os valores de referência 0,5 e 0,6 para as ciências sociais (quanto mais perto de 1 maior a consistência da escala), o nosso índice de diferenciação funcional apresenta uma fiabilidade alta ou elevada $(\alpha, 849)$. 
Religare, ISSN: 19826605, v.16, n.1, agosto de 2019, p.370-401.

itens, neste caso 13. Com efeito, procurámos indicadores que demonstrassem, transversalmente e de algum modo, a autonomização das diferentes esferas sociais (educação, saúde, assistência social, economia, transportes ou comunicação), a sua especialização (sobretudo, mas não exclusivamente, nos três primeiros indicadores listados) e a competição entre eles (nomeadamente, nos últimos seis itens listados, mas com particular destaque para os três últimos). Antes de prosseguirmos, é relevante explicar que, com estes indicadores e, em especial, com sua posterior medição e codificação, tivemos sempre em atenção o seguinte: quanto maior a dimensão das diferentes esferas sociais - ao nível dos recursos infraestruturais, humanos e financeiros -, quanto maior sua especialização institucional e técnica, quanto menor a regulação estatal à qual estão sujeitas e quanto melhores as condições para a sua livre competição, maior o nível de diferenciação funcional.

\section{Proposta de composição e medição do indice de diferenciação funcional}

Depois de determinarmos as duas dimensões e os 22 indicadores que medirão o nível de diferenciação funcional nos nossos países selecionados, iniciamos a construção de um índice de diferenciação funcional (variável independente) que nos possibilitará correlacionar sua intensidade face à nossa variável dependente religiosidade. Isso nos permitirá testar, mais empiricamente, essa teoria da secularização.

Com efeito, há uns anos que vimos estudando o fenômeno religioso em um grupo de países europeus. Temos investigado os fenômenos da secularização na Áustria, Eslováquia, Espanha, Itália, Polônia e Portugal ${ }^{9}$. No entanto, houve

\footnotetext{
9 Tal como exige o rigor científico, a seleção deste grupo de países respeita critérios amplos e objetivos. O primeiro prende-se com o fato de todos os países terem separação Estado-religiões. Ou seja, um secularismo positivo ou passivo, no qual o Estado promove e permite a atividade e visibilidade das religiões no espaço público. O segundo concerne à sua tipologia de relacionamento Estado-religiões. Os casos de estudo estão perto do conceito de principled distance, na medida em que é permitido, legalmente, ao Estado um tratamento diferenciado das várias igrejas e comunidades religiosas. Esta tipologia é baseada na separação com lei especial,
} 
Religare, ISSN: 19826605, v.16, n.1, agosto de 2019, p.370-401.

sempre dificuldades com o conceito de religião e, sobretudo, com as formas de medir sua centralidade na vida dos indivíduos. Por conta disso propusemos, no passado recente, a criação teórica e empírica de um índice de religiosidade ${ }^{10}$ que servisse de variável dependente e que fosse correlacionável com variáveis independentes como a diferenciação funcional ${ }^{11}$.

Por esse motivo, na construção deste índice seguiremos a estratégia metodológica aplicada no índice de religiosidade. Isso permitirá comparar com os mesmos instrumentos os dois índices e desenvolver um marco teórico e empírico sobre a construção de um índice de diferenciação funcional, algo sem precedentes no debate da secularização.

Importa, porém, ressalvar que se podem detetar algumas tentativas para medir esta teoria da secularização na literatura especializada. Como já denunciámos na seção acima, alguns autores alemães vêm trabalhando sobre este tópico, procurando medir a intensidade da diferenciação funcional nas sociedades europeias. Um dos primeiros modelos para calcular este fenômeno foi o de Chaves e Cann (1992), cuja intenção era medir apenas a primeira dimensão da diferenciação funcional (a separação) e, a partir daí, entender qual o impacto da regulação religiosa estatal na vitalidade religiosa. Para isso os autores utilizaram seis indicadores que pretendiam calcular a (in)existência de i) uma igreja de Estado, ii) do reconhecimento estatal de determinadas religiões, mas não de outras, iii) da indicação de líderes religiosos pelo Estado, iv) de

hierarquização de igrejas e liberdade religiosa. Por fim, o derradeiro critério foi a sua condição sociorreligiosa. Selecionámos apenas países de maioria católica apostólica romana, mas onde se têm verificado fenômenos de mutação religiosa. Em particular, com o crescimento de minorias religiosas e não religiosas e a fusão dos dois - o fenômeno dos crentes sem religião. Para mais desenvolvimentos sobre estes critérios de seleção cf. Moniz (2016).

${ }^{10} \mathrm{O}$ nosso índice de religiosidade é uma medida multidimensional, dividida em cinco dimensões de religiosidade - intelectual, ideológica, ritual, devocional e experimental - e composta por 22 indicadores. Na construção deste índice usaram-se as bases de dados mais recentes do WCD World Christian Database, do EVS - European Values Survey e do ESS - European Social Survey, aplicando-se ao nosso grupo de países selecionados. Os seus resultados são apresentados no gráfico 1, onde comparamos os níveis de religiosidade e diferenciação funcional. Para mais desenvolvimentos sobre a metodologia aplicada na construção do índice cf. Moniz (2018).

${ }^{11}$ Os resultados deste índice de religiosidade são visíveis no gráfico 1. 
Religare, ISSN: 19826605, v.16, n.1, agosto de 2019, p.370-401.

pagamento direto de salários ao pessoal religioso, v) de um sistema de arrecadação de impostos eclesiásticos e vi) do financiamento direto das despesas das instituições religiosas. Isto seria calculado através de dois valores: zero no caso da inexistência de uma dessas circunstâncias e um no caso da sua existência. Este modelo foi ulteriormente aperfeiçoado por Pollack e Pickel (2009). Os autores mantiveram o mesmo número de indicadores, mas alteraram alguns dos itens que compunham o modelo original. Por exemplo, com a consideração das capelanias militares ou prisionais ou da educação religiosa em escolas públicas Além disso, alteraram o modo de pontuar essa presença religiosa no espaço público, recorrendo a um modelo de zero a dois e oferecendo valores ponderados que conferiam maior relevância a uns itens e menos a outros. Por exemplo, a existência de uma igreja de Estado seria pontuada com dois, enquanto a existência de capelanias seria pontuada com um. A inexistência seria sempre pontuada com zero. Os estudos de Fox $(2008,2015)$ também procuram medir, através de vários índices compostos, tal como vimos nos dados da ARDA-RAS, o nível de envolvimento religioso dos governos. Para isso o autor recorreu, essencialmente, a quatro dimensões ${ }^{12}$ para medir a intensidade desse envolvimento. Neste caso, zero é o mínimo de envolvimento possível e dez o máximo. Outros modelos mais simples têm sido utilizados, como o de Pickel (2017) que analisa a diferenciação funcional à luz de dois indicadores micro, ou seja, baseados numa amostra da opinião individual dos indivíduos, a saber: i) os políticos não religiosos não são bons para o país e ii) os líderes religiosos não devem influenciar os governos. Embora sejam linhas de trabalho interessantes e nos tenham servido de base para, por exemplo, dar ênfase à dimensão separação da diferenciação funcional, nenhum destes índices cobre a real dimensão exigida pelos teóricos da secularização neste campo. Isto porque presumem, de forma simplista, que maior separação entre política e religião significa, natural e compulsoriamente, uma separação da religião das outras esferas sociais. Ora, por mais que até possa ser

12 As quatro primeiras citadas na dimensão separação Estado-religiões. 
Religare, ISSN: 19826605, v.16, n.1, agosto de 2019, p.370-401.

esse o caso, é necessário determinar e medir essa segunda dimensão da diferenciação funcional e entender se também nesses Estados, politicamente diferenciados, existe uma autonomização, especialização e competição de e entre outras esferas sociais.

É por esse motivo que consideramos necessária a criação de origem de um índice de diferenciação funcional que nos permita validar ou eventualmente refutar, com base empírica, os argumentos dos teóricos da secularização. Para cumprir esse desiderato, cada variável de cada dimensão do nosso índice foi redimensionada para um intervalo de 1 a 10 (correspondentes ao valor mínimo e máximo de diferenciação funcional, respetivamente) e codificada consoante a escala criada para cada item. A opção por uma escala de 10 valores prende-se, principalmente, com a nossa preocupação com a maximização das diferenças entre os casos de estudo. De fato, eles foram selecionados com base no desenho de investigação dos sistemas mais similares, onde se comparam casos com características semelhantes. Se, de um lado, isso confere coerência à escolha de nossos casos, favorecendo a constância das nossas variáveis; de outro lado, pode levar a variações de religiosidade e diferenciação funcional impercetíveis entre eles. Para se evitar uma excessiva homogeneização desses cenários e para se encontrar alguma variação, será útil o recurso a uma escala de 10 pontos, tal como Grim e Finke (2006) sugerem.

Cada um dos 22 itens do nosso modelo foi calculado através de um processo bastante simples, mas fiável. Primeiro multiplicamos por 100 o valor mínimo de cada item e depois dividimo-lo pelo valor máximo. Veja-se, por exemplo, o quadro 1 sobre o item Empresas em setores de alta-tecnologia.

\section{Exemplo de medição do item: Empresas em setores de alta-tecnologia (por 1.000 habitantes) [Quadro 1]}

\begin{tabular}{lcc}
\hline & \multicolumn{2}{c}{ Empresas em setores de alta-tecnologia (por 1.00o habitantes) } \\
\cline { 2 - 3 } & Valor médio bruto & Pontuação \\
\hline Áustria & 2.11 & \\
Itália & 1.83 & \\
Eslováquia & 2.00 \\
Espanha & 1.08 & \\
Polónia & 1.53 & \\
Portugal & 1.47 & \\
\hline Fonte: Eurostat (2008-2014) & & \\
Valores arredondados às centésimas & & \\
\hline
\end{tabular}


Religare, ISSN: 19826605, v.16, n.1, agosto de 2019, p.370-401.

No quadro 1 vb (valor médio bruto mais baixo) dos países selecionados é 1,08 e e o va (valor médio bruto mais alto) é 2,11. Seguindo o nosso cálculo, 1,08x100 é igual a 108 que dividido por 2,11 dá o resultado aproximado de 51. A diferença entre esse número (51) e 100 corresponde aproximadamente à percentagem de $49 \%$ que dista entre o $v b$ e o $v a$. A fórmula é, como frisámos, bastante simples:

$$
X=\frac{v b \times 100}{v a}
$$

Para se comprovar que o valor de $X(49 \%)$ corresponde precisamente à diferença do valor médio bruto entre os $v a$ e $v b$, procedemos a outro cálculo elementar $[(\mathrm{X} \div 100) \times v a]$. Assim sendo, a diferença entre ambos é 1,03 , valor que corresponde exatamente à distância de 49 pontos percentuais que aparta o va e o $v b$. Com o valor de $X$, pudemos começar a codificação das diferenças entre países por meio da nossa escala de 1 a 10.

Salvaguardamos que nem todos os indicadores da diferenciação funcional cobrem todo o nosso período temporal de análise. Por exemplo, no quadro 1 apenas temos dados para o período 2008-2014. Mas temos mais limitações ao nível da coleção de dados estatísticos, nomeadamente na primeira dimensão da diferenciação funcional, a separação Estado-religiões. Como vimos, ela é quase exclusivamente composta por dados agregados dos anos 2003 e 2008. Todavia, um número grande de indicadores cobre a maioria do nosso período de análise, como, por exemplo: recursos humanos em ciência e tecnologia (1999-2015), total de emprego nas áreas social e da saúde (1999-2015), entre outros. Os valores que surgem no quadro 1, bem como em todos os outros itens da diferenciação funcional, são o resultado da média aritmética simples do indicador empresas em setores de altatecnologia para os anos disponíveis (neste caso, 2008-14). Assim sendo, o valor 
Religare, ISSN: 19826605, v.16, n.1, agosto de 2019, p.370-401.

1,08 encontrado para Espanha é o resultado da média dos sete valores anuais ${ }^{13}$. Este e os outros valores foram ulteriormente codificados por meio da nossa escala de codificação que observamos no quadro 2.

\section{Exemplo de pontuação do item: Empresas em setores de alta-tecnologia (por 1.000 habitantes) [Quadro 2]}

\begin{tabular}{lcc}
\hline & \multicolumn{2}{c}{ Empresas em setores de alta-tecnologia (por 1.00o habitantes) } \\
\cline { 2 - 3 } & Valor médio bruto & Pontuação \\
\hline Áustria & 2.11 & 10 \\
Itália & 1.83 & 9 \\
Eslováquia & 2.00 & 10 \\
Espanha & 1.08 & 5 \\
Polónia & 1.53 & 7 \\
Portugal & 1.47 & 7 \\
& \\
\hline Escala de normalizacão 1-10: $0,11-0,30=1$ ponto; $0,31-0,50=2$ pontos; $0,51-0,70=3$ pontos; $0,71-0,90=4$ pontos; \\
$0,91-1,10=5$ pontos $1,11-1,30=6$ pontos; $1,31-1,50=7$ pontos; $1,51-1,70=8$ pontos; $1,71-1,90=9$ pontos; $1,91 »=10$ pontos \\
Fonte: Eurostat $(2008-2014)$ \\
Valores arredondados às centésimas
\end{tabular}

Ao se examinar o quadro 2, verifica-se que o $v b$ foi codificado com a pontuação 5 e o va com a pontuação 10. A distância de cinco pontos entre ambos é praticamente igual à diferença percentual real que os separa e que, neste indicador da diferenciação funcional, correspondeu ao nosso valor de $X$ (49\%). Aqui procurámos, o mais possível, aproximar a diferença pontual da tabela à diferença percentual real entre os valores intermédios, ou seja, aqueles que não são nem o va nem o $v b$. A título exemplificativo, a distância percentual entre os casos português e italiano é de aproximadamente $20 \%$. No quadro 2, o primeiro tem uma pontuação de 7 e o último tem uma pontuação de 9 . Essa diferença de dois pontos (que correspondem a $20 \%$, convertendo a escala para valores percentuais) corresponde precisamente a proporção da diferença entre ambos. Relembramos que este modelo não é perfeito, pois nem sempre conseguimos fazer corresponder as diferenças de todos os valores brutos à diferença pontual determinada pela nossa escala de normalização. Todavia, como já provámos, as

\footnotetext{
${ }^{13} \mathrm{O}$ nosso cálculo foi o seguinte: $(1,02+1,02+1,02+1,06+1,11+1,12+1,19) \div 7$. A média é de aproximadamente 1,08 .
} 
Religare, ISSN: 19826605, v.16, n.1, agosto de 2019, p.370-401.

diferenças são normalmente mínimas, não ultrapassando 1 ponto, ou seja $10 \%$ dessa diferença entre países.

Posto isto, e encontrado o valor de $X$ para cada país em cada indicador, passámos à etapa de codificação dos itens da diferenciação funcional. Observemos o quadro 3.

\section{Codificação dos itens da diferenciação funcional em todas as dimensões [Quadro 3]}

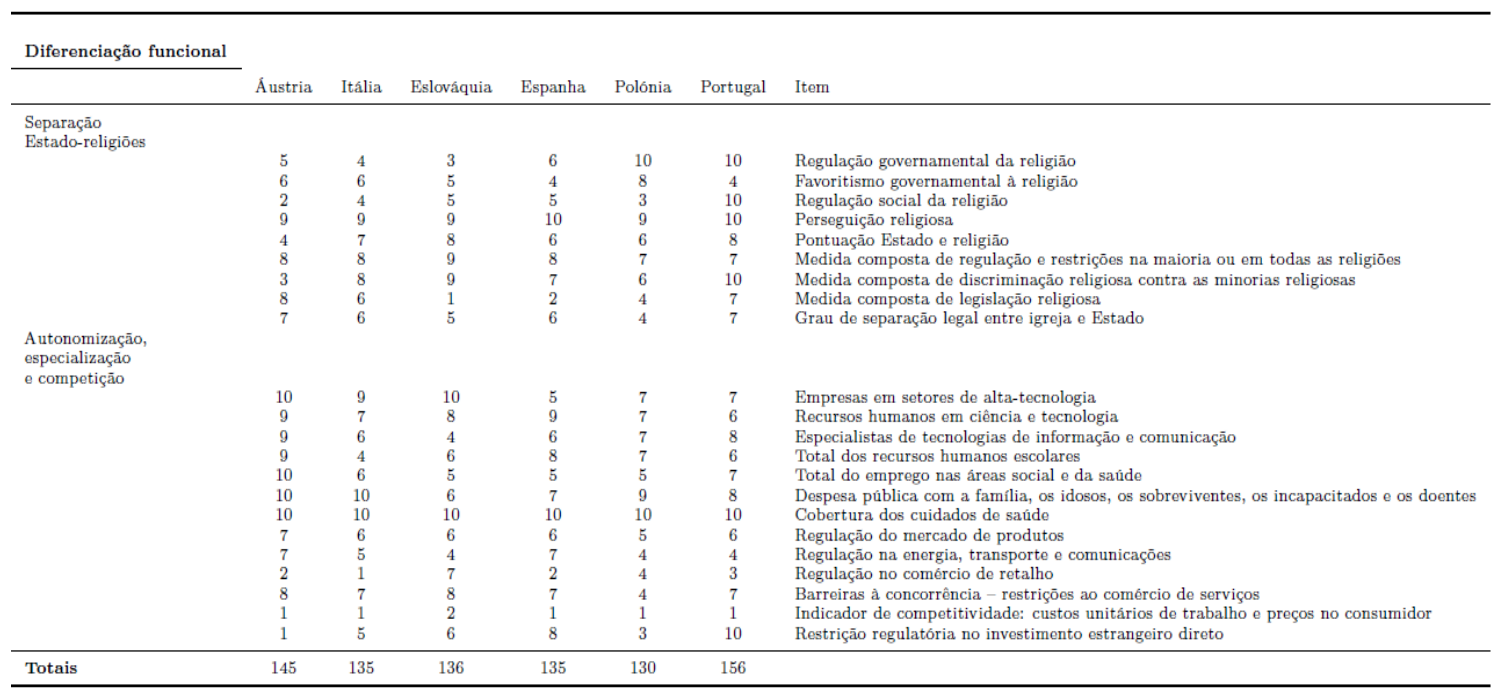

Fonte: compilação do autor, considerando as fontes já citadas

A maior pontuação possível para o conjunto dos 22 indicadores, por cada país, é 220. Quanto mais aproximado desta pontuação, maior será o nível de diferenciação funcional dos países. No quadro 3 verificamos que os valores são relativamente próximos. No entanto, Portugal surge como o país mais diferenciado funcionalmente, apresentando uma taxa bruta de diferenciação funcional de 156 pontos. O segundo mais diferenciado é a Áustria, com 145 pontos. Os restantes quatro países surgem com valores muito aproximados, entre os 136 (Eslováquia) e os 130 (Polônia, o país com menor diferenciação funcional).

Os valores brutos já nos dão uma ideia das diferenças entre os nossos casos de estudo; porém, por conta dos diferentes pesos que cada uma das dimensões da diferenciação funcional possui (a primeira é constituída por nove indiciadores e a segunda por treze). Para diminuirmos uma eventual discrepância de peso na 
Religare, ISSN: 19826605, v.16, n.1, agosto de 2019, p.370-401.

pontuação final da diferenciação funcional, procedemos ao cálculo da média aritmética simples de ambas, tal como é visível no quadro 4.

\section{Médias aritméticas simples de cada dimensão da diferenciação funcional} [Quadro 4]

\begin{tabular}{llccccc}
\hline & \multicolumn{5}{c}{ Diferenciação funcional } \\
\cline { 2 - 7 } & Áustria & Itália & Eslováquia & Espanha & Polónia & Portugal \\
\hline Separação Estado-religiões & 5.8 & 6.4 & 6.0 & 6.0 & 6.3 & 8.1 \\
$\begin{array}{l}\text { Autonomização, especializa- } \\
\text { ção e competição }\end{array}$ & 7.2 & 5.9 & 6.3 & 6.2 & 5.6 & 6.4 \\
\hline Médias & 6.5 & 6.2 & 6.2 & 6.1 & 6.0 & 7.2 \\
\hline
\end{tabular}

Fonte: compilação do autor, considerando as fontes iá citadas

Com o quadro 4 garantimos que estas duas dimensões da diferenciação funcional contribuem de igual modo (50\% cada) para a média final da diferenciação funcional. A hierarquia entre os países manteve-se praticamente inalterada. Há apenas uma mudança a assinalar, a Itália e a Eslováquia passam a ter pontuações iguais, enquanto a Espanha fica isolada como o segundo país menos diferenciado funcionalmente. Com este passo metodológico, nota-se, como pretendemos, o maximizar das diferenças entre os países. Por exemplo, a diferença entre o caso português e austríaco ou eslovaco era de 8\% e 13\% no quadro 3 e agora, no quadro 4, passou para 10\% e 14\% respetivamente. Este acentuar das diferenças, não foi, porém, suficiente para distingui-los Tendo em conta que as diferenças brutas entre os países selecionados não eram muito elevadas, o aumento das diferenças entre eles ajuda na definição de intervalos/níveis de classificação entre os países. Deste modo, estabelecemos cinco níveis de diferenciação funcional: entre 1,0 e 2,9 - muito baixa; entre 3,0 e 4,9 - baixa; entre 5,0 e 6,9 - média (por ordem crescente, Polônia, Espanha, Itália e Eslováquia e Áustria); entre 7,0 e 8,9 - alta (caso de Portugal); e entre 9,0 e 10 muito alta.

Mesmo se destacando como o único país com nível alto de diferenciação funcional, Portugal alcança esse patamar apenas de forma muito tangencial (duas 
Religare, ISSN: 19826605, v.16, n.1, agosto de 2019, p.370-401.

décimas acima do limite mínimo). O caso português se evidencia sobretudo por causa da sua pontuação na primeira dimensão da diferenciação funcional, uma diferenciação que poderíamos considerar mais do foro político. Com efeito, Portugal apresenta nessa diferenciação funcional política uma pontuação muito acima das médias dos outros países. Inversamente, a Áustria surge como o país menos diferenciado politicamente, sendo a sua posição final compensada apenas pela consideração da dimensão autonomização, especialização e competição, onde apresenta, destacadamente, o valor mais alto do conjunto. Se apenas essa dimensão fosse considerada, o caso austríaco seria aliás o único com nível alto de diferenciação funcional. Os outros países têm, grosso modo, pontuações aproximadas tanto numa como noutra dimensão da diferenciação funcional, distando uns dos outros, no máximo pouco mais do que seis décimas.

Em resumo, podemos afirmar que, deste conjunto, Portugal é o mais diferenciado funcionalmente, sendo seguido pela Áustria e pelos restantes quatro países que apresentam taxas de diferenciação funcional muito similares. Também devemos destacar o número de países no nível médio de diferenciação funcional e a ausência de casos nos e a sua distância pontual significativa para os extremos (muito baixo e muito alto) da nossa grelha classificativa. Isso pode querer dizer que, no que toca à separação das esferas religiosas da política e no que concerne à autonomização, especialização e competição entre as diferentes esferas sociais, estes países tendem a não ser muito diferentes.

\section{Correlação entre diferenciação funcional e religiosidade}

Após o cálculo dos níveis de diferenciação funcional para cada país, seguimos para a sua comparação com o índice de religiosidade, a nossa variável dependente. Neste caso, procuramos testar a proposição dos teóricos da secularização que diz que mais diferenciação funcional significa menos religiosidade. Comecemos a aferição dessa asserção mediante a análise preliminar do gráfico 1. 
Religare, ISSN: 19826605, v.16, n.1, agosto de 2019, p.370-401.

\section{Colunas com a relação entre os níveis de religiosidade e de diferenciação} funcional [Gráfico 1]

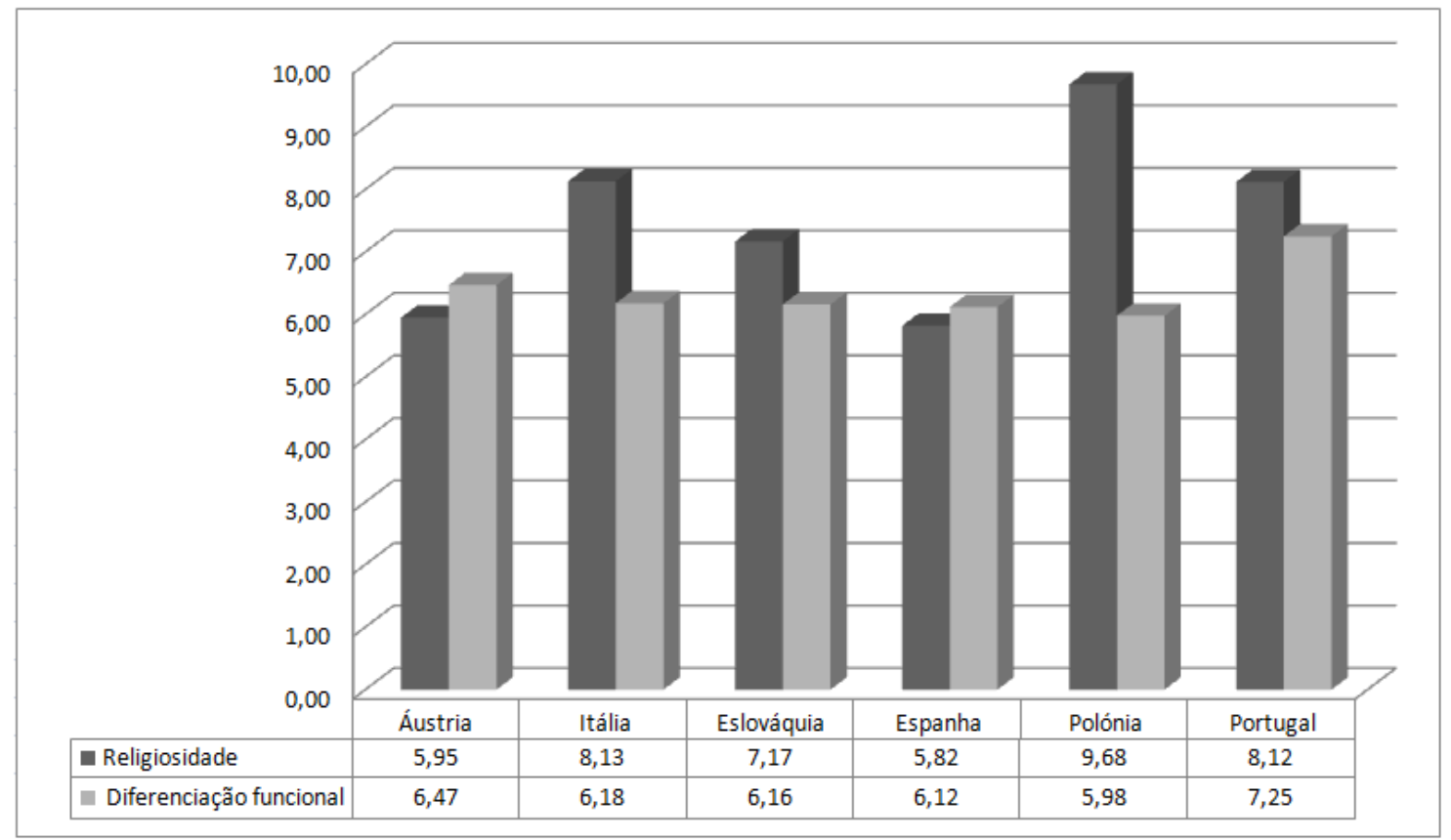

Fonte: compilação do autor, considerando as fontes já citadas

Tal como viemos indicando, a parca diferença entre os valores da diferenciação funcional entre os países dificulta a deteção de algum padrão particular. Se, por um lado, a Polônia é o país, simultaneamente, mais forte na variável dependente (religiosidade) e mais fraco na variável independente (neste caso, a diferenciação funcional); por outro lado, a Espanha ou a Áustria (os países com níveis de religiosidade mais baixos) não são os mais diferenciados funcionalmente. $\mathrm{O}$ caso espanhol é ainda mais sintomático das dificuldades de encontrar um padrão, porquanto é o segundo menos diferenciado e o menos religioso. Portugal, um dos países mais religiosos é, por seu turno, o mais diferenciado, estando distante, ao nível da diferenciação, em mais de um ponto da Itália, com quem partilha praticamente o mesmo nível de religiosidade. Assim sendo, nenhum destes casos de estudo permite corroborar a ideia da secularização que diz que a diferenciação funcional tem tendencialmente consequências negativas nos fenômenos religiosos. Todavia, o contrário também não parece ser verdade. Ou seja, mais diferenciação funcional não parece ser um bom preditor dum elevado nível de religiosidade. Se no caso português isso 
Religare, ISSN: 19826605, v.16, n.1, agosto de 2019, p.370-401.

poderia ser discutível, porque é um dos países com maior taxa de religiosidade e o que tem maior diferenciação funcional, no caso polonês, a afirmação iria, precisamente, no sentido oposto: aí menos diferenciação é sinônima de mais religiosidade. Não parece, portanto, haver qualquer correlação (positiva ou negativa) entre os índices de religiosidade e de diferenciação funcional. Observemos o gráfico 2, para melhor compreendermos esta aparente falta de correlação.

\section{Religiosidade vs. Diferenciação funcional (posição relativa dos países na respetiva ordenação) [Gráfico 2]}

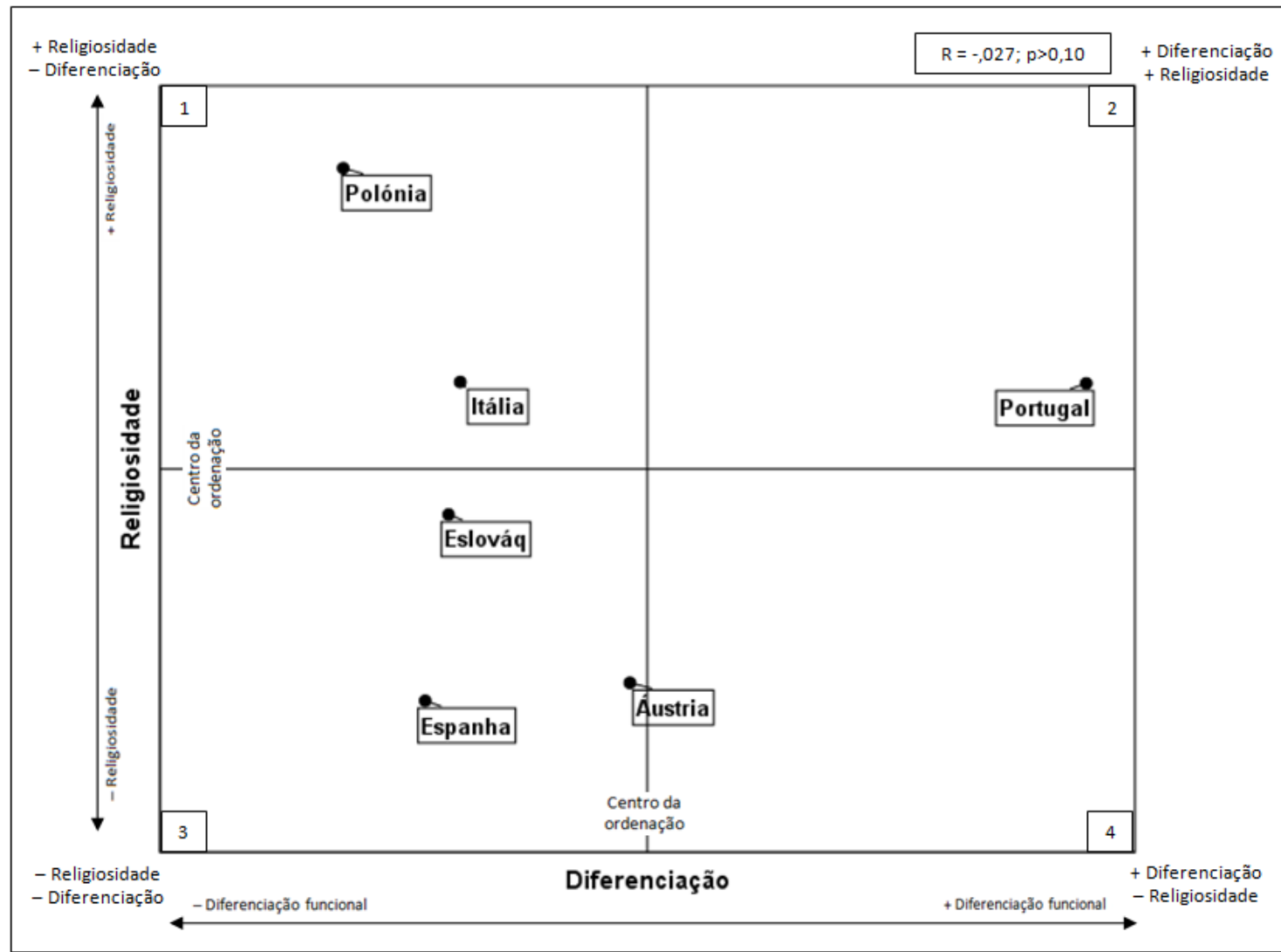

Fonte: cálculos do autor, considerando as fontes já citadas

No gráfico 2 temos a relação entre os valores da série de $\mathrm{Y}$ (o índice de religiosidade) e os de X (o índice de diferenciação funcional). Ao analisá-lo podemos entender um pouco melhor o que o gráfico 1 já denunciava: existe uma 
Religare, ISSN: 19826605, v.16, n.1, agosto de 2019, p.370-401.

correlação negativa muito fraca ${ }^{14}$ entre a variável dependente e a independente, não sendo estatisticamente significativa $(r(6)=-0,027 ; p>0,10)^{15}$.

No gráfico 2, importa, antes de mais, sublinhar o fato de o quadrante 4, o único que estaria de acordo com os pressupostos dos teóricos da secularização mais diferenciação é igual a menos religiosidade -, estar vazio. Não obstante a Áustria se aproxime dessa asserção da secularização, o nosso estudo não permite comprovar essa proposição ao nível da diferenciação funcional. Ao continuarmos a análise do gráfico, percebemos que, apesar da correlação negativa muito fraca entre as variáveis, podemos registar a existência de um certo padrão. No quadrante 3 encontramos os três países menos religiosos, sendo que eles estão também no conjunto dos menos diferenciados. Outro ponto a sublinhar é o fato de que os dois países mais religiosos se encontram juntos no quadrante 1, sendo, simultaneamente dos menos diferenciados funcionalmente. Portugal, nomeadamente pela sua elevada pontuação relativa na variável diferenciação funcional é o único país que se encontra isolado em um quadrante, estando colocado no destinado aos países mais religiosos e mais diferenciados.

Dada a aparente inexistência de correlação e a consequente dificuldade de encontrar um padrão entre as variáveis, verifiquemos se, pelo menos, alguma das dimensões da diferenciação funcional tem uma correlação menos fraca com a variável dependente. Examine-se o quadro 5.

\section{Correlações entre a religiosidade e as dimensões da diferenciação funcional} [Quadro 5]

\begin{tabular}{lcc}
\hline Religiosidade & \multicolumn{2}{c}{ Diferenciação funcional } \\
\cline { 2 - 3 } & Separação Estado-religiões & Autonomização, especialização e competição \\
\hline Correlação de Pearson &, 431 &,$- 756^{*}$ \\
Sig. (bilateral) &, 394 &, 082 \\
$\mathrm{~N}$ & 6 & 6 \\
\hline \hline
\end{tabular}

*As correlações são significativas no nível 0,10 (bilateral)

\footnotetext{
14 Neste campo, seguimos a seguinte classificação padronizada: 0: ausência de correlação; +/- ]0 0,25]: muito fraca; +/- ]0,25 - 0,40]: fraca; +/- ]0,40 - 0,60]: moderada; +/- ]0,60 - 0,75]: moderada forte; +/- ]0,75 - 0,90]: forte; +/- ]0,90 - 1[: muito forte; +/- 1: correlação perfeita. Cf. (BRITES, 2015; MARÔCO, 2018; MARÔCO \& GARCIA-MARQUES, 2006)

${ }^{15} \mathrm{O}$ valor exato do nível de significância é ,960.
} 
Religare, ISSN: 19826605, v.16, n.1, agosto de 2019, p.370-401.

Dois elementos se destacam no quadro 5. Primeiro, se analisadas individualmente, ambas as dimensões da diferenciação funcional têm correlações mais fortes com a religiosidade. Em particular, a dimensão autonomização, especialização e competição que apresenta, ainda que tangencialmente, uma correlação (negativa) forte com a variável dependente, sendo essa correlação estatisticamente significativa $(r(6)=-0,756 ; p<0,10)$. Segundo, a dimensão separação Estado-religiões tem uma correlação positiva com a variável dependente, ainda que moderada e não significativa estatisticamente $(r(6)=0,431 ; p>0,10)$. Isso reforça a ideia de que o argumento da secularização sobre a relação (negativa) entre separação Estado-religiões e a religiosidade não se pôde comprovar, porque, ainda que de forma moderada, a relação entre ambas se afigura saudável. Ou seja, quanto mais diferenciadas funcionalmente as sociedades mais religiosas tendem a ser e não o oposto como sugerem os teóricos da secularização ${ }^{16}$.

Efetivamente, na correlação da dimensão autonomização, especialização $e$ competição com a variável dependente, verifica-se uma concentração dos três países com maiores níveis de religiosidade (Polônia, Itália e Portugal) no mesmo quadrante dos países mais religiosos e menos autonomizados, especializados e competitivos. A proximidade da Eslováquia do quadrante dos menos religiosos e mais autonomizados, especializados e competitivos e o destaque da Áustria nesse mesmo quadrante ajudam a explicar a razão por detrás dessa correlação

\footnotetext{
${ }^{16}$ Isso não significa dizer que alinhemos com a teoria clássica da economia religiosa que diz, contrariamente aos pressupostos da secularização, que a separação Estado-religiões não limita a capacidade das igrejas e comunidades religiosas em reter membros, antes aumenta-a. Ou seja, preconiza a ideia de que a maiores níveis de liberdade das igrejas e comunidades acompanhados, necessariamente, por maior competitividade no mercado religioso e por maior especialização dos produtores de bens religiosos - corresponderão níveis mais altos de religiosidade. Não concordamos com essas asserções, porque, primeiramente, nos países selecionados, não existe propriamente um verdadeiro mercado religioso (entendido enquanto um espaço onde os indivíduos consideram que podem fazer diferentes escolhas religiosas e que todas são válidas e não constrangidas por uma ou mais maiorias), e, em segundo lugar, porque, muitos estudos têm provando que o modelo da economia religiosa não tem aplicação na Europa. Pelo contrário (BILLIET et al., 2003; NORRIS \& INGLEHART, 2004; OPFINGER, 2011), no continente, segundo esses estudos, há uma inversão dos próprios pressupostos da economia religiosa.
} 
Religare, ISSN: 19826605, v.16, n.1, agosto de 2019, p.370-401.

negativa forte. Se retirássemos a Espanha dessa dimensão da diferenciação funcional teríamos uma correlação negativa muito forte (quase linear) entre autonomização, especialização e competição e religiosidade, sendo estatisticamente significativa $\left(r(5)=-0,931 ; p<0,05^{17}\right)$. Assim sendo, esta é a única versão da teoria da secularização sobre a diferenciação funcional - a autonomização funcional dos vários sistemas sociais e a sua transformação em subsistemas sociais especializados que competem entre si - que parece ter ainda alguma força empírica para sustentar a teoria de que mais diferenciação funcional significa menos religiosidade.

Por outro lado, a dimensão separação Estado-religiões, o núcleo da diferenciação funcional, não pôde ser apoiada pelos nossos resultados empíricos. Isso já havia sido de certo modo corroborado, embora por meio de outras estratégias metodológicas, de outros bancos de dados e de outros propósitos investigacionais, nomeadamente por Pollack (2009) ou, indiretamente, pelos trabalhos de Fox (2008) sobre os níveis de envolvimento estatal na religião. Pollack (2009, p. 158), em particular, mostra que é difícil encontrar algum efeito da separação Estado-religiões na vitalidade do campo religioso. Todavia, mesmo quando deteta algum efeito, sobretudo ao nível da frequência ao culto - um indicador da nossa dimensão ritual da religiosidade -, ele contraria o pressuposto da secularização, pois a capacidade integradora e a intensidade da religião aumentam em situações de menor diferenciação funcional do Estado face à religião.

Em suma, a teoria da secularização que diz que mais diferenciação funcional é igual a menos religião, não foi comprovada pelo nosso exame empírico. Não parece haver correlação entre estas variáveis. A única dimensão da diferenciação funcional que parece ter alguma sustentação empírica é a autonomização, especialização e competição, porque nos permitiu provar que, tendencialmente, quanto mais esta dimensão está presente, menos religiosos são 
Religare, ISSN: 19826605, v.16, n.1, agosto de 2019, p.370-401.

os indivíduos. Por seu turno, a tese do impacto da separação Estado-religiões na religiosidade não pôde ser corroborada empiricamente. A correlação desta dimensão da diferenciação e a religiosidade, existindo, tende a ser positiva, contrariando diametralmente os teóricos da diferenciação funcional. Ou seja, os fenômenos de maior diferenciação funcional tendem a estar presentes nos países com maiores índices de religiosidade.

\section{Comentário final}

A nossa investigação permitiu chegar a três conclusões essenciais. Primeira e principalmente ajuda-nos a entender que, para o conjunto dos países analisados e através da metodologia aplicada, a teoria da secularização, que diz que as sociedades mais diferenciadas funcionalmente são menos religiosas, não tem validade empírica. Com efeito, os nossos dados mostram que a diferenciação funcional explica cerca de 3\% da variação (negativa) na religiosidade. No geral, a diferenciação funcional tem um impacto negativo na religiosidade. Contudo, esses efeitos são exclusivamente visíveis na sua dimensão autonomização, especialização e competição. Ela ajuda a explicar cerca de $76 \%$ da sua variação negativa. No global, as proposições dos muitos teóricos da diferenciação funcional sobre o modo como ela, por meio das suas dimensões, tende a reduzir os sistemas religiosos tradicionais a subsistemas sociais indiferenciados, fazendoos, por consequência, perder sua relevância microssocial, não têm, porém, ressonância empírica.

Em segundo lugar, os pressupostos da secularização que advogam que mais diferenciação, nomeadamente na sua dimensão nuclear (separação Estadoreligiões), significa menos religiosidade, não puderam ser comprovados pelo nosso estudo. Com efeito, a dimensão separação Estado-religiões ajuda, pelo contrário, a explicar cerca de $43 \%$ da variação (positiva) na religiosidade. Ou seja, de acordo com os nossos resultados, ainda que de forma moderada, a separação entre estas esferas sociais está positivamente correlacionada com o 
Religare, ISSN: 19826605, v.16, n.1, agosto de 2019, p.370-401.

desenvolvimento da religiosidade. Apesar de já termos justificado e sublinhado que essa conclusão não nos aproxima da teoria da economia religiosa (que diz que maior separação é igual a maior vitalidade religiosa) será necessário aprofundar o porquê desse resultado. Consideramos que a própria ação dos Estados europeus, pela sua experiência recente de separação com cooperação, com base nos tais princípios das twin tolerations e do principled distance, é crucial nessa matéria, devendo ser investigada caso-a-caso. Ou seja, o fato de os Estados poderem dispor de uma relação de separação com cooperação estratégica com determinadas igrejas e comunidades religiosas, promovendo, através delas, determinados valores sociais (explícita ou implicitamente religiosos), pode permitir desenvolvimentos positivos no que toca a determinadas formas de religiosidade (mais ou menos institucionais), mesmo considerando os seus elevados níveis formais de separação.

Em terceiro lugar, e inversamente à anterior, a dimensão autonomização, especialização e competição tem uma correlação fortemente negativa com a variável dependente. Os nossos resultados parecem satisfazer as proposições da diferenciação funcional que asseveram que, com a hipercomplexidade da modernização, os distintos sistemas sociais se autonomizam, especializam e aumentam sua competitividade, de modo a que nenhum sistema social consegue dominar, como sucedia no passado. Desse modo, os sistemas sociais religiosos, sobretudo os tradicionais (com estruturas mais pesadas e menos dinâmicas e competitivas), transformam-se em subsistemas indiscriminados (mais um operador na vasta e complexa moldura de sistemas sociais), tendendo a perder relevo na prossecução de certas funções sociais. Ou seja, esses fenômenos da diferenciação parecem estar forte e negativamente correlacionados com o desenvolvimento positivo da religiosidade.

Enfim, o nosso trabalho provou que é mais recompensador repensar, rever ou atualizar as teorias da secularização, à luz da realidade social contemporânea, do que abandoná-las. Ou seja, por oposição aos críticos da secularização que 
Religare, ISSN: 19826605, v.16, n.1, agosto de 2019, p.370-401.

admitem largar totalmente o modelo da secularização ou mudar a direção das suas pesquisas, por conta do acúmulo de críticas aos seus pressupostos teóricos e empíricos, consideramos que a secularização ainda nos oferece um quadro útil para a perceção da situação religiosa nas sociedades modernas, nomeadamente nas europeias, e, por isso, as suas proposições não devem ser descartadas levemente. A (re)teorização, operacionalização e mensuração da diferenciação funcional e a sua correlação com uma medida composta de religiosidade tem, no nosso ver, tanto de desafiante (pelo modo como os resultados desafiam e atestam, em simultâneo, os pressupostos da secularização) como de urgente, de modo a que se entenda que consequências (revitalização, mutação ou declínio?) os processos da modernidade (que são tão não-deterministas como direcionados por diferentes agentes) têm na religiosidade.

No entanto, este estudo é apenas um primeiro passo nesse sentido. Será ainda necessário aumentar as bases de dados disponíveis e, por consequência, refinar os modelos de construção de índices. Será preciso estudar outras variáveis independentes relevantes, como as teorias clássicas (racionalização e societalização) da secularização ou as suas atualizações teóricas (segurança existencial). Será fundamental explorar novas grelhas analíticas, como as migrações internacionais, a diversidade cultural ou o terrorismo. Será inevitável examinar diferentes contextos regionais, englobando mais países (cuja comparação se justifique e seja cientificamente relevante) nas análises empíricas. No fundo, como nos disse profeticamente Berger (2014), será necessário estudar os vários altares da modernidade, religiosos ou não religiosos, e entender o paradigma (mutável e que tanto pode significar revitalização, declínio ou transformação) da religião nas sociedades hodiernas. Deixamos, portanto, esses reptos aos cientistas sociais que estejam tão engajados quanto nós em entender os efeitos (positivos ou negativos) dos processos da modernidade na religiosidade.

\section{Referências}


Religare, ISSN: 19826605, v.16, n.1, agosto de 2019, p.370-401.

BELLAH, Robert N. The broken covenant: american civil religion in time of trial. Nova Iorque: Seabury Press, 1975.

BEN-PORAT, Guy; FENIGER, Yariv. Unpacking secularization: structural changes, individual choices and ethnic paths. Ethnicities, v. 14, n. 1, p. 91-112, 2014.

BERGER, Peter. The sacred canopy: elements of a sociological theory of religion. Nova Iorque: Anchor Books, 1990 [1967].

BERGER, Peter. The Desecularization of the World, a Global Overview. In: BERGER, Peter (ed.). The desecularization of the world: Resurgent Religion and World Politics. Michigan: Grand Rapids, 1999.

BILLIET, Jakk et al. Church commitment and some consequences in western and Central Europe. In: PIEDMONT, Ralph L.; MOBERG, David O. (eds.). Research in the Social Scientific Study of Religion. Leiden: Brill, 2003. p. 129-160.

BRITES, Rui. Análise de dados com IBM SPSS®: Mix essencial para relatórios profissionais e teses académicas. Módulo I - Básico, Lisboa: ISEG, 2015.

CASANOVA, José. Reconsiderar la secularización: una perspectiva comparada mundial. Revista Académica de Relaciones Internacionales, n. 7, p. 1-20, 2007.

CASANOVA, José. The secular, secularizations, secularisms. In: CALHOUN, Craig; JUERGENSMEYER, Mark; ANTWERPEN, Jonathan Van (eds.). Rethinking secularism. Nova Iorque: Oxford University Press, 2011.

CHAVES, Mark; CANN, David E. Regulation, pluralism, and religious market structure: explaining religion's vitality. Rationality and Society, v. 4, n. 3, p. 272290, 1992.

DEMERATH, Jay. Secularization and Sacralization, Deconstructed and Reconstructed. In: BECKFORD, James; DEMERATH, Jay (eds.). The sage handbook of the sociology of religion. Londres: Sage Publications, 2007.

DURKHEIM, Émile. The division of labor in society. Trad. W. D. Halls, Nova Iorque: Free Press, 1984 [1893].

EISENSTADT, Shmuel. Multiple modernities. Daedalus, v. 129, n. 1, p. 1-30, 2000. FOX, Jonathan. A world survey of religion and the state. Cambridge: Cambridge University Press, 2008.

FOX, Jonathan. Political secularism, religion, and the state: a time series analysis of worldwide data. Col. Cambridge Studies in Social Theory, Religion and Politics. Cambridge: Cambridge University Press, 2015.

GORSKI, Philip. Historicizing the secularization debate: church, state, and society in late medieval and early modern Europe, ca. 1300 to 1700 . American Sociological Review, v. 65, n. 1, p. 138-167, 2000.

GRIM, Brian; FINKE, Roger. International religion indexes: government regulation, government favoritism, and social regulation of religion. Interdisciplinary Journal of Research on Religion, v. 2, n. 1, p. 1-40, 2006.

HABERMAS, Jürgen. Between naturalism and religion: philosophical essays. Trad. Ciaran Cronin. Cambridge: Polity, 2008.

HALIKIOPOULOU, Daphne. Patterns of secularization: church, state and nation in greece and the republic of Ireland. Farnham: Ashgate, 2011. 
Religare, ISSN: 19826605, v.16, n.1, agosto de 2019, p.370-401.

HELLEMANS, Staf. Secularization in a religiogeneous modernity". In: LAERMAN et al. (eds.), Secularization and social integration: Papers in honor of Karel Dobbelaere. Col. Sociology Today, v. 4. Lovaina: Leuven University Press, 1998. p. 67-82.

LUCKMANN, Thomas. The invisible religion: the problem of religion in modern society. Nova Iorque, Macmillan, 1967.

LUHMANN, Niklas. Social systems. Trad. J. Bednarz Jr.; D. Baecker, Stanford, Stanford University Press, 1995.

MARÔCO, João. Análise estatística com o SPSS Statistics. 7. ed. Pêro Pinheiro: ReportNumber, 2018.

MARÔCO, João; GARCIA-MARQUES, Teresa. Qual a fiabilidade do alfa de Cronbach? Questões antigas e soluções modernas?. Laboratório de Psicologia, v. 4, n. 1, p. 65-90, 2006.

MARTIN, David. A general theory of secularization. Oxford, Blackwell, 1978.

MARTIN, David. On Secularization: toward a revised general theory. Burlington, Vt.: Ashgate, 2005.

MONIZ, Jorge Botelho. A secularização na ultramodernidade católica européia: uma proposta de análise contextual e multidimensional do fenômeno da secularização. Em Tese, v. 13, n. 1, p. 188-219, 2016.

MONIZ, Jorge Botelho. Múltiplas modernidades, múltiplas secularizações e secularização contextual: novas perspectivas sobre o estudo sociológico da religião. Religião $\mathcal{E}$ Sociedade, v. 37, n. 3, p. 125-149, 2017a.

MONIZ, Jorge Botelho. As camadas internas da secularização: proposta de sistematização de um conceito essencialmente contestado. Sociologia: Revista da Faculdade de Letras da Universidade do Porto, v. 34, p. 73-92, 2017b.

MONIZ, Jorge Botelho. Índice de religiosidade: uma proposta de teorização e medição dos fenómenos religiosos contemporâneos. Revista Brasileira de História das Religiões, v. 11, n. 32, 2018.

NORRIS, Pippa; INGLEHART, Ronald. Sacred and secular: religion and politics worldwide. Cambridge: Cambridge University Press, 2004.

OPFINGER, Matthias. Religious Market Theory vs. Secularization: The Role of Religious Diversity Revisited. Hannover Economic Papers, 2011. p. 1-32.

PARSONS, Talcott. Structure and process in modern societies. Nova Iorque: Free Press, 1960.

PICKEL, Gert. Contextual secularization. Theoretical thoughts and empirical implications. Religion and Society in Central and Eastern Europe, v. 4, n. 1, p. 3-20, 2011.

PICKEL, Gert. Secularization - an empirically consolidated narrative in the face of an increasing influence of religion on politics. Politica $\mathcal{E}$ Sociedade, v. 36, n. 16, p. 259-294, 2017.

POLLACK, Detlef; PICKEL, Gert. Church-State relations and the vitality of religion in European comparison. In: PICKEL, Gert; MÜLLER, Olaf (eds.). Church and religion in contemporary Europe. Results from Empirical and Comparative Research. Wiesbaden: Springer-Verlag, 2009. p. 145-166. 
Religare, ISSN: 19826605, v.16, n.1, agosto de 2019, p.370-401.

RUESCHEMEYER, Dietrich. Structural differentiation, efficiency, and power. The American Journal of Sociology, v. 83, n. 1, p. 1-25, 1977.

WILSON, Bryan. Religion in secular society: a sociological comment. Harmondsworth: Penguin Books, (1969 [1966]).

WILSON, Bryan. Religion in secular society: fifty years on. In: BRUCE, Steve (ed.). Oxford: Oxford University Press, 2016.

WOHLRAB-SAHR, Monika; BUCHARDT, Marian. Revisitando o secular: secularidades múltiplas e trajetórias para a modernidade. Política E Sociedade, v. 16, n. 36, p. 143-173, 2017.

\section{Sites}

EUROSTAT. Disponível em: https://ec.europa.eu/eurostat/data/database. Acesso em: 31 jul. 2018.

OCDE - Organização para a Cooperação e Desenvolvimento Económico. Disponível em: https://data.oecd.org/. Acesso em: 31 jul. 2018.

RAS - The Religion and State Project, ARDA, Association of Religion Data Archives, Bar-Ilan University. Disponível em: http://www.thearda.com/ras/. Acesso em: 14 jul. 2018.

Recebido em 06-08-2018.

Aprovado em 12-03-2019. 